\title{
Impact of electromagnetic field on the pathogenicity of selected entomopathogenic bacteria (Proteus sp. and Bacillus sp.) on tick (Rhipicephalus decoloratus)
}

\author{
Omoya, F. O. ${ }^{1 *}$, Kelly, B. A. ${ }^{2}$ and Akinyosoye, F. A. ${ }^{1}$ \\ ${ }^{1}$ Federal University of Technology, Akure. Ondo State. Nigeria. \\ ${ }^{2}$ Wesley University and Technology, Ondo, Ondo State, Nigeria.
}

Accepted 14 June, 2013

\begin{abstract}
The effect of exposing entomopathogenic bacteria isolated from tick (Rhipicephalus decoloratus) to variable intensities of electromagnetic field for different periods of time was examined on their pathogenicity on tick. Some bacterial isolates from the macerate of tick cadavers were used in the infection of healthy engorged ticks. Two of the bacteria tested namely Proteus mirabilis and Bacillus cereus were able to induce morbid conditions in the ticks both of which were re-isolated from the resulting tick cadavers. Re-infection of different concentrations of both entomopathogenic bacteria of ticks were carried out on the tested ticks to determine the minimum lethal concentration required for pathogenicity. The result reveals that $P$. mirabilis and $B$. cereus were able to cause disease at concentrations of $10^{6}$ and $10^{7} \mathrm{cfu} / \mathrm{ml}$, respectively. These bacteria were then exposed to electromagnetic field with different intensities for different periods of time after which they were reinfected into healthy insects. Conclusively, the study reveals some signs of stimulation in the entomopathogenic potency of $B$. cereus after exposure to electromagnetic field (EMF) when compared to the control treatments while a significant reduction in the entomopathogenic potency of $\boldsymbol{P}$. mirabilis was recorded.
\end{abstract}

Key words: Entomopathogens, electromagnetic field, Proteus mirabilis, Bacillus cereus.

\section{INTRODUCTION}

Ticks are known as vectors of human and other animal disease agents. They are significant for public health mainly because of the zoonotic disease agents transmitted by them which include an array of bacterial, viral and protozoan disease agents (Harwood and James, 1979; Goodman et al., 2005). In humans, tens of thousands of cases of tick - borne diseases caused by these agents occur annually.

Ticks feed on blood during some or all stages in their life cycle; that is, they are obligate ecto- parasites. In addition, tick bites can cause toxic reactions, allergic responses and fatal paralysis or even anaphylactic reactions (Van Wye et al., 1991). Given the scale of the harmful effects of ticks, it is essential to control their population. Present control methods of ticks involve application of acaricides to infested cattle which may produce undesirable side effects on non target organisms. To reduce our reliance on these chemical products, it is necessary to embark on programs that are environmentally friendly.

The aim of this study was to assess the pathogenicity efficacy of some entomopathogenic bacteria on tick as a biocontrol measure and to check whether the entomopathogenic efficacy of these bacteria will be enhanced or reduced after their exposure to electromagnetic field. 


\section{MATERIALS AND METHODS}

\section{Sample collection}

The adult ticks (Rhipicephalus decoloratus) used were carefully picked from cattle at the teaching and research farm of the Federal University of Technology Akure research farm located at Oba Kekere campus. The ticks were observed for lack of lethargy and activeness. They were artificially engorged upon their transfer to the laboratory by maintaining them on fresh supply of bovine blood in sterile petri dishes covered with silica gel. The temperature of the environment was maintained around $37^{\circ} \mathrm{C}$. Morbid and mortal conditions were monitored through lethargy, inactiveness, reduced feeding, no change in size and colour change.

\section{Isolation of bacteria from tick cadavers}

Resulting tick cadavers were picked aseptically and macerated inside sterile mortar with $10 \% \mathrm{NaCl}$ solution as a buffer. Serial dilutions of the macerate were carried out and the appropriate diluents using sterile water were plated on both general and selective bacterial media. The media used include nutrient agar for the general growth of bacteria, Maconkey Agar and Eosine methylene blue agar for the growth of enteric bacteria, deoxychocolate citrate agar for the growth of Salmonella and Shigella and mannitol salt agar for the growth of Staaphylococcus aureus. The media were prepared according to manufacturer's specification and sterilized in the autoclave at $121^{\circ} \mathrm{C}$ for $15 \mathrm{~min}$. The media were allowed to cool to suitable temperature before pouring on the plates. After solidification of the media, plates were inoculated with $0.1 \mathrm{~mL}$ of $10^{6}$ and $10^{7}$ of the macerate diluent at $37^{\circ} \mathrm{C}$ for $24 \mathrm{~h}$.

\section{Purification and identification of isolated bacteria cells}

Each distinct and visible colonies were obtained on the above named selective and general purpose media. In order to identify the different bacteria obtained in the cultures, cultural and biochemical characterizations were performed according to the methods of Fawole and Oso (2001), Barnett et al. (2000) and Harrigan (1998).

\section{Preparation of bacterial suspensions for the infection of tick}

Proteus mirabilis and Bacillus cereus were grown in nutrient broth which was incubated at $37^{\circ} \mathrm{C}$ for $24 \mathrm{~h}$. The turbid cultures after incubation were centrifuged at 2,500 rpm for $15 \mathrm{~min}$ in order to harvest the cells. $10^{6}$ of the harvested cells were washed in normal saline and used for this study. Calculation was based on plating 1 $\mathrm{mL}$ of the serially diluted sample which was physically enumerated on plates after incubation.

\section{Infection of tick with isolated bacteria}

Ticks ( $R$. decoloratus) were infected by immersion in bacterial suspensions prepared from all the different bacterial types previously isolated. Controls were immersed in sterile water. The immersions of the ticks into the bacterial suspensions were carried out according to the methods of Drummond and Gladney (1969). Infected ticks were observed for $120 \mathrm{~h}$ for colour change, lethargy and death (Figure 1).
Isolation of bacteria from infected ticks to confirm entomopathogenicity

Ticks with disease symptoms and dead ticks were selected after infection and macerated inside a sterile mortal using $10 \% \mathrm{NaCl}$ solution as a buffer. The resulting extracts were plated on generalized and differential media earlier stated for the isolation and possible recovery of the bacteria used on the infection.

\section{Determination of the minimum lethal bacterial concentration necessary for pathogenicity}

The minimum bacterial concentration needed for pathogenicity was determined by infecting the insects with various concentrations of the recorded entomopathogens. The least concentration showing pathogenic activity was calculated and recorded after observing for $120 \mathrm{~h}$. The number of bacteria was calculated by diluting the suspension serially and plating $1 \mathrm{~mL}$ of the serially diluted sample which was physically enumerated on plates after incubation (Figures 2 and 3 ).

\section{Exposure of entomopathogens to different magnetic fields}

The intensity of magnetic field was measured and standardized in total floor area of solenoid at $41 \mathrm{mT}$. Different test preparations were exposed to different intensities of electromagnetic fields with voltage $(9,10$ and $12 \mathrm{~V})$. The control experiment was not exposed to any radiation treatment before infection.

\section{Infection of ticks with irradiated cells}

After the entomopathogens are exposed to different intensities of magnetic field for different periods of time (30,60, 90, 120 and 150 $\mathrm{min}$ ) to become irradiated which were used to infect a new healthy batch of ticks. The infection of ticks was done through the immersions of the ticks into the bacterial suspensions $10^{6}$ for $60 \mathrm{~s}$ in accordance with the methods of Drummond and Gladney (1969). Unexposed cells of the same concentration were also prepared for each of the bacterial entomopathogens and used for infection of a different batch of ticks to serve as positive control while noninfected ticks were used as negative controls.

\section{Statistical analysis}

All data were expressed as mean \pm SEM. Statistical analysis was performed using ANOVA. Inter-group comparism was achieved by Duncan multiple range test using SPSS window 15. Differences were judged to be statistically significant when $P$ was less than 0.05 .

\section{RESULTS AND DISCUSSION}

A total number of seven bacterial species were isolated from the ticks before and after infection with the entomopathogens. These are S. aureus, Pseudomonas aeruginosa, Streptococcus pyogenes, B. cereus, Bacillus subtilis, P. mirabilis and Escherichia coli (Table 1). After infection with all of cultured bacteria isolates, only $B$. cereus and $P$. mirabilis showed to have entomopathogenic effects.

Concentration values of $2.9 \times 10^{7}$ and $2.4 \times 10^{7} \mathrm{cfu} / \mathrm{ml}$ for 


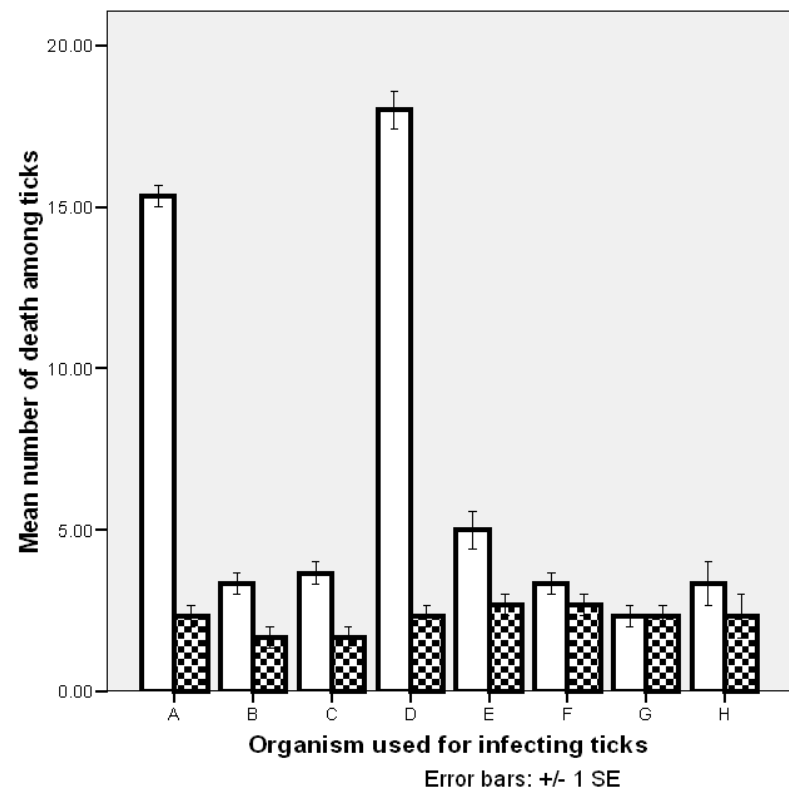

呙 $\times$

Figure 1. Infection of ticks with isolated bacteria after $120 \mathrm{~h}$. A, $B$. cereus; B, E. coli; C, B. licheniformis; D, Proteus mirabilis; E, P. aeruginosa; F, S. aureus; G, S. pyogenes; H, B. subtilis; IX, infected ticks; $X$, control ticks; $X$-axis shows the mean number of morbid ticks after infection; $Y$-axis shows the organisms used in the infection of these ticks. Bacteria used in this study were isolated from ticks, culture in nutrient broth, centrifuged, washed and suspended in sterile water. The bacterial suspensions are then used to infect the ticks. Standard error $=$ \pm 1 .

Table 1. Bacterial isolates obtained from tick before and after infection.

\begin{tabular}{|c|c|c|c|c|c|c|c|}
\hline Organism & E. coli & S. aureus & $P$. aeruginosa & S. pyogenes & B. cereus & B. subtilis & P. mirabilis \\
\hline \multicolumn{8}{|c|}{ Cultural characteristic } \\
\hline Pigment & White & White & Green & White & Yellowish white & White & White \\
\hline Shape & Circular & Circular & Irregular & Irregular & Undulate irregular & Circular & \\
\hline Elevation & Raised & Raised & Flat & Raised & Flat & Flat & Raised \\
\hline Surface & Moist & Moist & Wet & Moist & Dry & Dry & Moist \\
\hline \multicolumn{8}{|c|}{ Morphological characteristic } \\
\hline Gram reaction & - & + & - & - & + & + & - \\
\hline Cell Shape & Rods & & Rods & & Rods & Rods & Rods \\
\hline Spore formation & - & - & - & - & + & + & - \\
\hline \multicolumn{8}{|c|}{ Biochemical characteristic } \\
\hline Catalase & + & + & + & + & + & + & + \\
\hline Coagulase & + & + & - & - & - & - & + \\
\hline Oxidase & - & - & + & - & + & - & - \\
\hline \multicolumn{8}{|c|}{ Sugar fermentation test } \\
\hline Glucose & $A G$ & $A G$ & $A G$ & $A G$ & $A G$ & $A G$ & $A G$ \\
\hline Galactose & - & $A G$ & - & $A G$ & $A G$ & $A G$ & - \\
\hline Sucrose & $A G$ & $A G$ & $A G$ & - & $A G$ & $A G$ & $A G$ \\
\hline Lactose & $A G$ & $A G$ & - & $A G$ & - & $A G$ & $A G$ \\
\hline Mannitol & $\mathrm{AG}$ & $\mathrm{AG}$ & $\mathrm{AG}$ & $\mathrm{AG}$ & $\mathrm{AG}$ & $\mathrm{AG}$ & $A G$ \\
\hline
\end{tabular}

AG, Acid and gas production; A, acid production; -, negative; +, positive. 


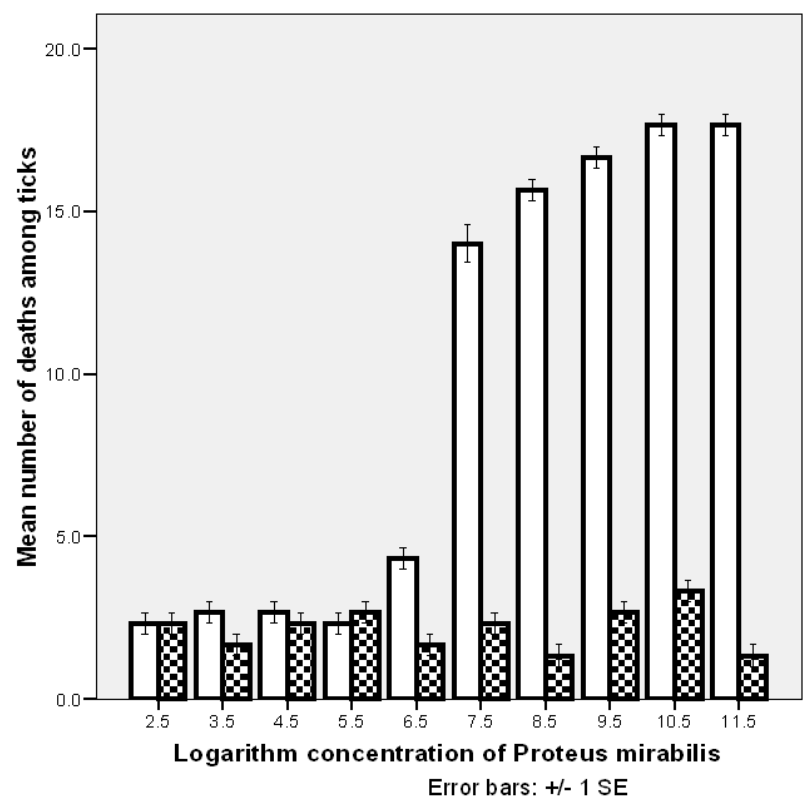

Figure 2. Minimum lethal concentration of Proteus mirabilis against ticks. Proteus mirabilis used in this study were isolated from ticks, culture in nutrient broth, centrifuged, washed and suspended in sterile water. The bacterial suspensions were diluted serially into ten places. Each of the dilutions was used to infect the ticks. Y-axis represents the mean number of tick deaths that occurred after infection with Proteus mirabilis; X-axis represents the logarithmic values in cfu/ml of Proteus mirabilis concentration used in the infection of the ticks. Standard error $= \pm 1$.

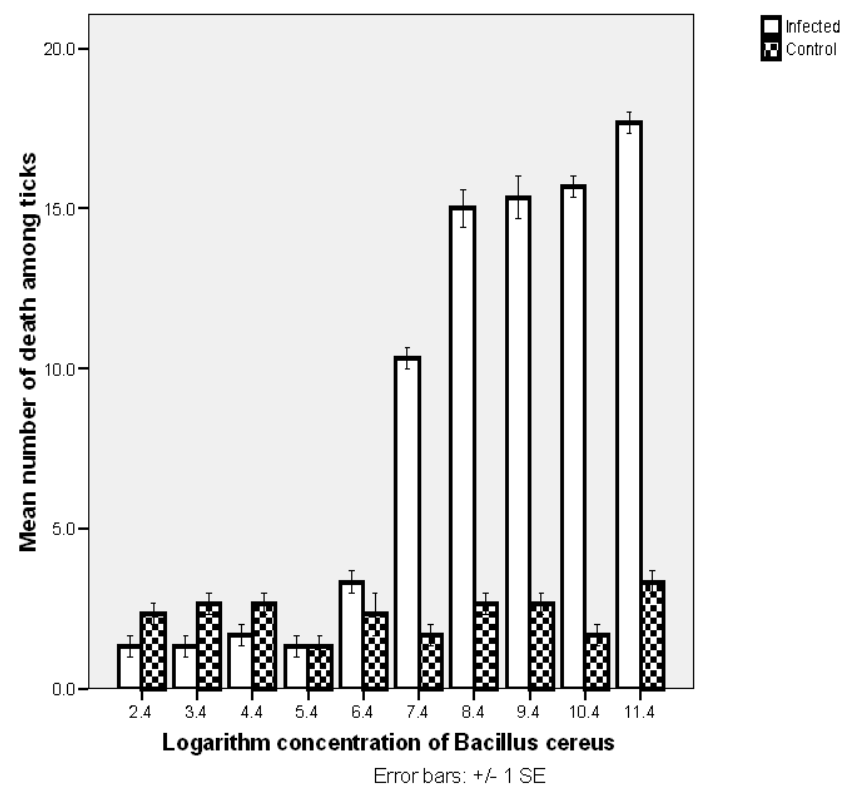

Figure 3. Minimum lethal concentration of $B$. cereus against ticks. $B$. cereus used in this study were isolated from ticks, culture in nutrient broth, centrifuged, washed and suspended in sterile water. The bacterial suspensions were diluted serially into ten places. Each of the dilutions was used to infect the ticks. $Y$ - axis represents the mean number of tick deaths that occurred after infection with $B$. cereus. $X$ - axis represents the logarithmic values in cfu/ml of $B$. cereus concentration used in the infection of the ticks. Standard error $= \pm 1$. 


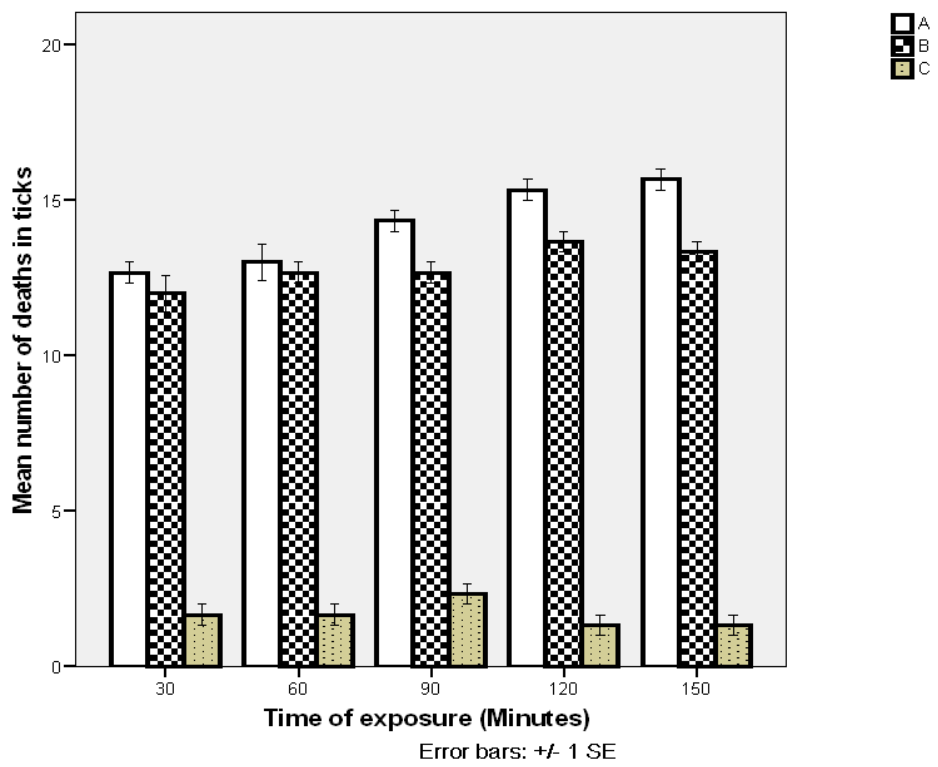

Figure 4. Infection of ticks with $B$. cereus exposed to $8 \mathrm{~V}$ electromagnetic field. A, Ticks infected with exposed cells; B, ticks infected with unexposed cells; C, uninfected ticks. B. cereus used in this study were isolated from ticks sourced from cattle at FUTA teaching and research farm. It was cultured in nutrient broth, centrifuged, washed and suspended in sterile water. The bacterial suspensions were diluted to the minimum lethal concentration. The dilution was exposed to electromagnetic radiation of $8 \mathrm{~V}$ input after which it was used to infect the ticks. $Y$ - axis represents the mean number of tick deaths that occurred after infection with radiated $B$. cereus. X-Axis represents the exposure time in minutes of $B$. cereus suspension to electromagnetic field. Standard error $= \pm 1$.

$P$. mirabilis and $B$. cereus, respectively were the least bacterial concentrations that showed signs of pathogenicity on infected ticks (Figure 2). B. cereus responded positively to the radiation in terms of its pathogenic effects on the ticks when compared to the control. There were slight increases in their pathogenic potency after radiation intensities of 8 and $10 \mathrm{~V}$ while at $12 \mathrm{~V}$ the increase became more pronounced. After exposing $P$. mirabilis to the radiation, an initial slight decrease in their pathogenic potency was observed at radiation intensities of 8 and 10 Volts. These inhibitory effects increased at radiation value of 12 Volts (Figures 4 to 9 ).

Bacterial isolates obtained from ticks ( $R$. decoloratus) used in this study $S$. pyogenes, E. coli, P. mirabilis and B. cereus are similar to what Benson et al. (2003) described after the isolation of intracellular symbionts and other bacteria associated with ticks. This study suggests that $B$. cereus is a potential entomopathogen as a result of the lethargic effects it caused among the ticks used in this study which subsequently results to their death. This is in accordance with the findings of Lawrence and Joel (1997) who reported various Bacillus sp. as potential entomopathogens which have been used extensively for the control of insect and arachnids populations in domestic, crops, forests, and the aquatic environment. Mortality observed could be as a result of the ingestion of bacteria. The ticks were able to ingest $P$. mirabilis and $B$. cereus in the suspensions through their mouth parts. This is similar to the submissions of Knulle and Rudolph (1982) who worked on the infection of ticks with bacterial suspensions.

Our results suggest that electromagnetic field treatment can significantly reduce the entomopathogenic potency of $P$. mirabilis when compared to the control test where untreated $P$. mirailis was used in infecting ticks. This is in agreement with the findings of Roha and Mohammad (2005) who found that electromagnetic field treatments significantly reduced the growth and proliferation of bacteria such as $E$. coli and $S$. aureus in culture when compared to the controls. In addition, according to Hoffman (1985), exposure of some bacterial cells to electromagnetic fields causes inhibition of the growth, reproduction and activities of such microorganisms. This reduction in potency can be attributed to the loss of the bond between the vital cell protein and its ions. Vital cell protein refers to essential protein present in microbial cells. They contribute to the maintenance of the cell structure and integrity. Thus, in the event of the loss between the protein and its ions, there will be alteration in the normal physiological functioning of the cell thus leading to the loss of entomopathogenicity. According to Pothakamury et al. (1993), exposure of certain microorga- 


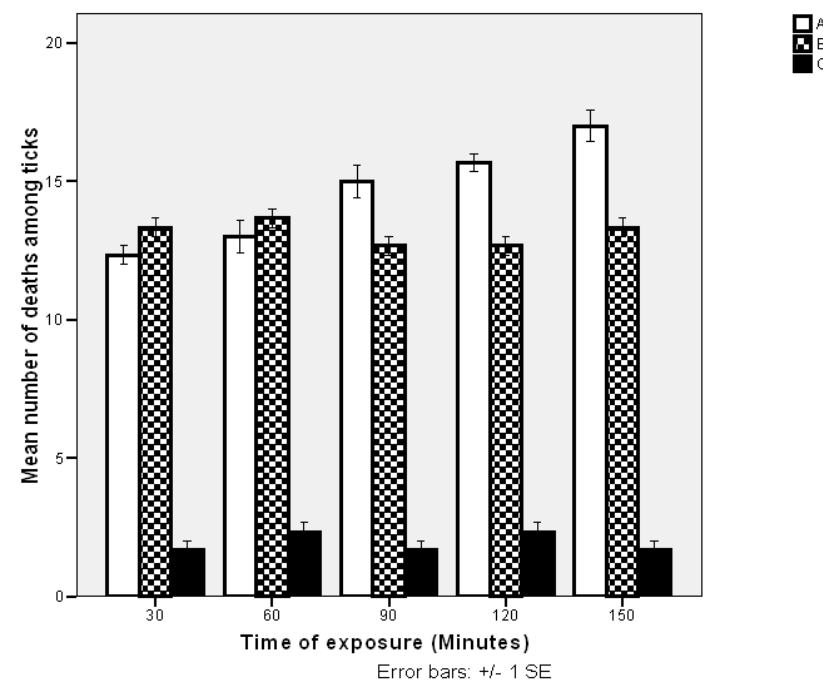

Figure 5. Infection of ticks with $B$. cereus exposed to $10 \mathrm{~V}$ electromagnetic field. A, Ticks infected with exposed cells; B, ticks infected with unexposed cells; $C$, uninfected ticks. B. cereus used in this study were isolated from ticks sourced from cattle at FUTA teaching and research farm. It was cultured in nutrient broth, centrifuged, washed and suspended in sterile water. The bacterial suspensions were diluted to the minimum lethal concentration. The dilution was exposed to electromagnetic radiation of $10 \mathrm{~V}$ input after which it was used to infect the ticks. Y-axis represents the mean number of tick deaths that occurred after infection with radiated $B$. cereus. $X-$ Axis represents the exposure time in minutes of $B$. cereus suspension to electromagnetic field. Standard error $= \pm 1$.

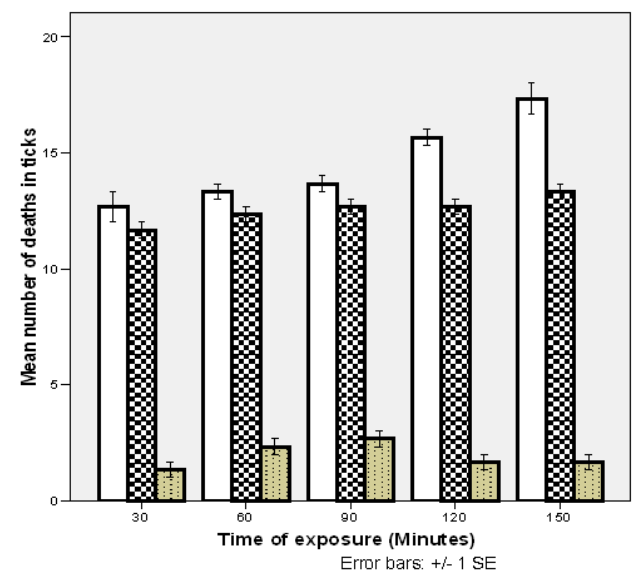

Figure 6. Infection of ticks with $B$. cereus exposed to $12 \mathrm{~V}$ electromagnetic field. A, Ticks infected with exposed cells; $B$, ticks infected with unexposed cells; $C$, uninfected ticks. $B$. cereus used in this study were isolated from ticks sourced from cattle at FUTA teaching and research farm. It was cultured in nutrient broth, centrifuged, washed and suspended in sterile water. The bacterial suspensions were diluted to the minimum lethal concentration. The dilution was exposed to electromagnetic radiation of 12 volts input after which it was used to infect the ticks. $Y$ axis represents the mean number of tick deaths that occurred after infection with radiated $B$. cereus.X- axis represents the exposure time in minutes of $B$. cereus suspension to electromagnetic field. Standard error $= \pm 1$. 


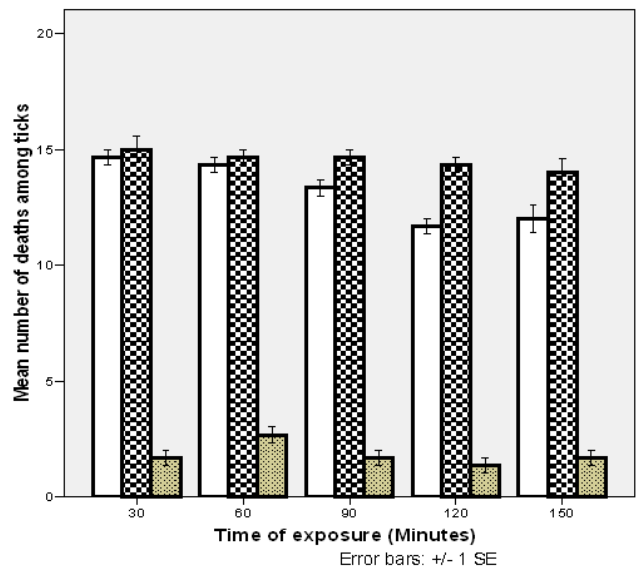

周㝵

Figure 7. Infection of ticks with Proteus mirabilis exposed to $8 \mathrm{~V}$ electromagnetic field. A, Ticks infected with exposed cells; B, ticks infected with unexposed cells; C, uninfected ticks. Proteus mirabilis used in this study were isolated from ticks sourced from cattle at FUTA teaching and research farm. It was cultured in nutrient broth, centrifuged, washed and suspended in sterile water. The bacterial suspensions were diluted to the minimum lethal concentration. The dilution was exposed to electromagnetic radiation of 8 Volts input after which it was used to infect the ticks. Y- axis represents the mean number of tick deaths that occurred after infection with radiated Proteus mirabilis. X-axis represents the exposure time in minutes of Proteus mirabilis suspension to electromagnetic field. Standard error $= \pm 1$.

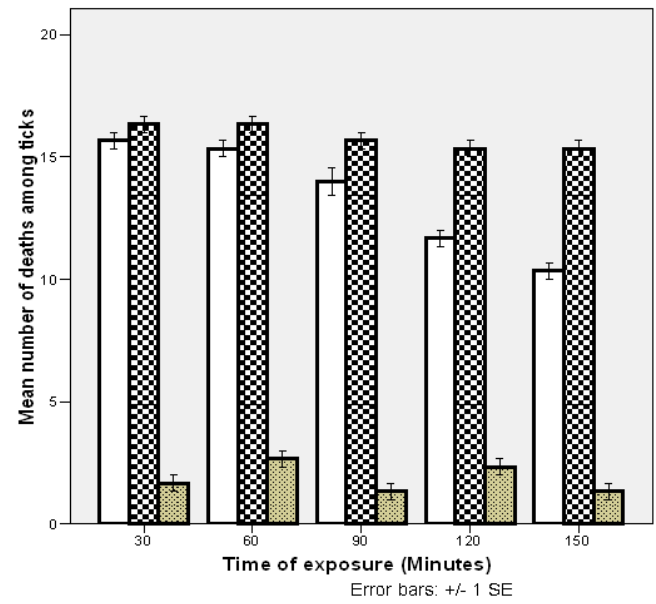

䀦

Figure 8. Infection of ticks with Proteus mirabilis exposed to $10 \mathrm{~V}$ electromagnetic field. A, Ticks infected with exposed cells; B, ticks infected with unexposed cells; $C$, uninfected ticks. Proteus mirabilis used in this study were isolated from ticks sourced from cattle at FUTA teaching and research farm. It was cultured in nutrient broth, centrifuged, washed and suspended in sterile water. The bacterial suspensions were diluted to the minimum lethal concentration. The dilution was exposed to electromagnetic radiation of 10 Volts input after which it was used to infect the ticks. Y- axis represents the mean number of tick deaths that occurred after infection with radiated Proteus mirabilis. X-axis represents the exposure time in minutes of Proteus mirabilis suspension to electromagnetic field. Standard error $= \pm 1$. 


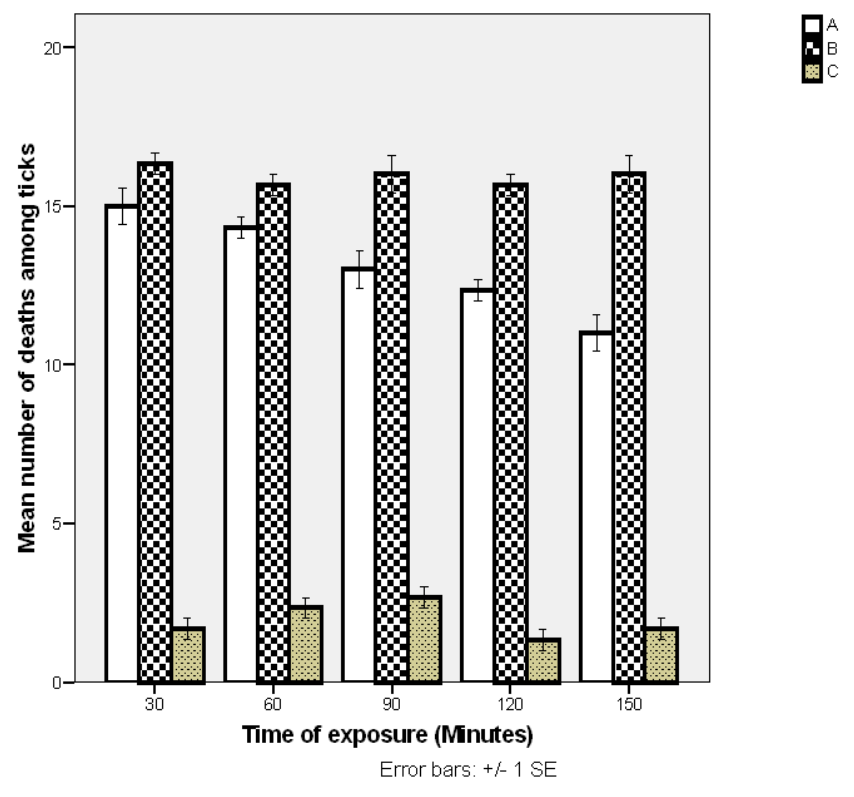

Figure 9. Infection of ticks with Proteus mirabilis exposed to $12 \mathrm{~V}$ electromagnetic field. A, Ticks infected with exposed cells; B, ticks infected with unexposed cells; C, uninfected ticks. Proteus mirabilis used in this study were isolated from ticks sourced from cattle at FUTA teaching and research farm. It was cultured in nutrient broth, centrifuged, washed and suspended in sterile water. The bacterial suspensions were diluted to the minimum lethal concentration. The dilution was exposed to electromagnetic radiation of 12 volts input after which it was used to infect the ticks. $Y$ - axis represents the mean number of tick deaths that occurred after infection with radiated Proteus mirabilis. X-axis represents the exposure time in minutes of Proteus mirabilis suspension to electromagnetic field. Standard error $= \pm 1$.

nisms to electromagnetic field treatment can result in the cleavage of the covalent bonds in the DNA

molecule and subsequent inhibition of the growth and activities of such microorganisms.

Furthermore, our study suggests that there is an increase in $B$. cereus pathogenic potency after an electromagnetic treatment which is similar to what of Yoshimura (1989) found where certain bacteria responds positively well in terms of increased growth rate and activities to electromagnetic field treatment. In conclusion, exposure of the entomopathogenic bacteria $B$. cereus to electromagnetic field causes a significant increment in their degradative ability on ticks, hence, this organism might be a potential biocontrol agent for controlling ticks.

\section{ACKNOWLEDGEMENTS}

Prof. Babatunde Rabiu and Mr. Olusola of the Physics Department of the Federal University of Technology Akure, Nigeria are appreciated for their technical support in the provision of the electromagnetic field apparatus used in this work.

\section{REFERENCES}

Barnett JA, Payne RW, Yarrow D (2000). Yeast: Characteristics and identification. $3^{\text {rd }}$ Edition, Cambridge university press, Cambridge, England. 111-125.

Fawole MO, Oso BA (2001). Laboratory manual in Microbiology. $3^{\text {rd }}$ Edition. 102-105.

Goodman JL, Dennis DT, Sonenshine DE (2005). Tick-borne diseases of humans. Washington, DC: ASM Press.

Harrigan WF (1998). Laboratory methods in Food Microbiology, $3^{\text {rd }}$ Edition, Academic press, San Diego California. 36-84.

Harwood RF, James MT (1979). Entomology in human and animal health $\left(7^{\text {th }}\right.$ ed.). New York; Macmillian Publishing Co.

Knulle W, Rudolph D (1982). Humidity relationships and water balance of ticks - In Physiology of Ticks. 43-70. Oxford, Pergamon Press.

Lawrence AL, Joel PS (1997). Safety and ecotoxicology of entomopathogenic Bacteria.

Micah JB, Jeffrey DG, Douglas EE, David RB (2003). Intracellular symbionts and other bacteria associated with deer ticks (Ixodes scapularis) from Nantucket and Wellfleet, Cape Cod, Massachusetts

Pothakamury UR, Babosacanovas GV, Swanson BG (1993). Magnetic field inactivation of microorganisms and generation of biological changes. Food Technol. 47(12):85-93

Roha KK, Mohammad RS (2005). Effect of static electric field treatment on multiple antibiotic-resistant pathogenic strains of Escherichia coli and Staphylococcus aureus. J. Microbiol Immumol Infect. 38:394-398

Vanwye JE, Hsu YP, Terr AI, Lane RS, Moss RB (1991). Anaphylaxis from a tick bite. The New England J. Med. (324):774-778.

Yoshimura M (1989). Application of magnetic action for sterilization of food. Shokukin Kihatsu 23(3):46- 48. 